\title{
Biogeographical patterns of the diet of Palearctic badger: Is badger an earthworm specialist predator?
}

\author{
LI Feng ${ }^{1,2}$, LUO ZhenHua $^{1,2}$, LI ChunLin $^{1,2}$, LI ChunWang $^{1} \&$ JIANG ZhiGang ${ }^{1,2 *}$ \\ ${ }^{1}$ Key Laboratory of Animal Ecology and Conservation Biology, Institute of Zoology, Chinese Academy of Sciences, Beijing 100101, China; \\ ${ }^{2}$ University of Chinese Academy of Sciences, Beijing 100049, China
}

Received May 15, 2012; accepted July 31, 2012; publihsed online January 14, 2013

Badgers were hypothesized as an earthworm specialist predator. We reviewed spatial patterns and food habits of the Eurasian badger (Meles spp.) in relation to geographical variables like latitude, elevation, aspects, and environmental variables, such as temperature, snow cover depth, precipitation, primary productivity, and human influence. The relative frequencies of occurrence of food items in the diets of badgers in 19 studies across 22 localities worldwide were included in the analysis plus the data from our study on the badger diet on the Qinghai-Tibetan Plateau. Principal component analysis (PCA) was used to extract the main components of dietary composition. Multiple regression analysis was applied to reveal the relationship between trophic diversity and the main PCA factors and biogeographical variables. We found a clear latitudinal gradient in the dietary composition of badgers, which was characterized by a greater consumption of insects and reptile in southern area and a higher intake of earthworm in northern regions. Nevertheless, badgers are not an earthworm specialist predator. Furthermore, trophic diversity of badger diets was significantly positively correlated with latitude and human activity. Abundance and availability of foods appear to determine badger foraging tactics. Badgers are adept in exploiting local resources and our results confirm that badgers are generalist predators with opportunistic foraging behavior across their entire distribution range.

environmental factor, feeding ecology, generalist, latitude gradient, trophic diversity

Citation: $\quad$ Li F, Luo Z H, Li C L, et al. Biogeographical patterns of the diet of Palearctic badger: Is badger an earthworm specialist predator?. Chin Sci Bull, 2013, 58: 2255-2261, doi: 10.1007/s11434-012-5650-9

Carnivores are key species in ecosystems. Geographical factors affect food availability and have an impact on dietary composition and diversity of animals. For example, the diet of European otter (Lutra lutra) is more diverse in the southern localities than in the northern areas [1]. There are also obvious latitudinal gradients in the dietary compositions of wildcat (Felis silvestris) [2], martens (Martes spp.) [3] and red fox (Vulpes vulpes) [4]. Wildcats eat more rabbits in lower latitude but more rodents in higher latitude [2]. Pine martens (Martes martes) consume more mammals and birds in northern regions but more vegetable matter in southern regions [3]. Red fox preys on more lagomorphs and invertebrates in southern areas but eats more small mammals and fruits in northern areas. Additionally, red fox

*Corresponding author (email: jiangzg@ioz.ac.cn) eats more lagomorphs in lower elevation but more small mammals in higher elevation [4]. Environmental variables also play important roles in the feeding ecology of animals. For example, temperature has an obvious effect on food diversity for martens [3] and precipitation affects the prey abundance of little brown bat (Myotis lucifugus) [5]. For brown bears (Ursus arctos), their consumption of vertebrates increases as the duration of snow cover and snow depth increases, and as temperature, precipitation and primary productivity increase, their consumption of invertebrates increases accordingly [6]. Studies on the relationships between feeding habits and biogeographical variables for endangered carnivore species provide useful information on how to better protect these animals, which also help us understand the carnivore ecology and their life history strategies [7]. 
The genus Meles is widespread across the Eurasia. Some researchers classify the taxa as a single species (M. meles) $[8,9]$ whereas some researchers classify it into three species: European badger (M. meles), Asian badger (M. leucurus) and Japanese badger (M. anakuma) [10]. Here, we take the badgers across the Eurasia as a single species. The feeding ecology of badger has been the subject of numerous studies at many localities throuth out its distribution range, such as in England [11], Italy [12-20], Hungary [21], Ireland [22], Poland [23], Japan [24], Mongolia [25], Scotland [26], Spain [27-29] and Swiss [30]. Some researchers argued that badger is an earthworm specialist predator [26,31]; while other studies indicated that the badger is a generalist predator that uses resources according to its availability $[19,27$, 29]. Badger shows high plastic trophic diversity: rabbits, insects, and fruits are potential foods for badgers. Hence, badger is an opportunistic predator.

Roper et al. [32] reviewed the badger diet across the former Soviet Union and concluded that the badger is a generalist forager with a preference for animal foods. Goszczynski et al. [23] studied the effect of geographical factors such as latitude or habitat type on badger diets in Europe and revealed that badger mainly consume earthworm and fruits and badger diet composition had latitude gradient. However, no study has been done to explore the potential relationships between dietary composition of badgers and environmental variables such as temperature, precipitation, primary productivity and snow cover across the entire distribution range of badgers. Here, we reviewed the literatures, then described the food spectra of the badger over its entire distribution range and assessed the effect of environmental variables on badgers.

We tested whether badgers are generalist predators with opportunistic foraging behavior in this study. In detail, we (i) evaluated the main food groups consumed by badges in relation to geographical variables (latitude and elevation), (ii) interpreted patterns in the diet of badgers from a biogeographical perspective, and (iii) tested the competing ideas that badgers are generalists or specialists across their distribution ranges.

\section{Materials and methods}

\subsection{Review of badger diet studies}

We conducted a thorough literature search in the existing databases and selected publications about badger diet that met the following criteria: (1) diet data covered at least the whole activity period of badgers in one year; (2) the sample size exceeds 60; (3) sufficient information was provided so that we could calculate the relative frequency of occurrence of food items; (4) adequate information regarding the geographical location of the study area was provided; and (5) dietary composition was accessed using stomach/scat samples. Cases in Roper and Mickevicius' review did not meet the above criteria [32]; we thus dropped the reference from the analyses. Altogether, 19 publications based on data from 22 locations were selected for this analysis (Figure 1 and Table 1) plus the results from our field study on badger diet in the Qinghai Lake basin on the Qinghai-Tibetan Plateau, China. The dietary composition of badgers in our result was obtained through scat analysis: badger faeces were soaked in water thoroughly and washed through two sieves with mesh sizes of 5 and $1 \mathrm{~mm}$, respectively. Then the remaining of samples on the sieves were distinguished into the food categories (Appendix S1). Our results indicated insects were the main foods in the diet of badgers in the Qinghai Lake basin, its frequency of occurrence and relative frequency accounted $100 \%$ and $68.45 \%$, respectively, in complementary with plateau pika (Ochotona curzoniae), birds, Qinghai toad-headed agamid lizard (Phrynocephalus vlangalii), and fruits of ephedra (Ephedrna intermedia).

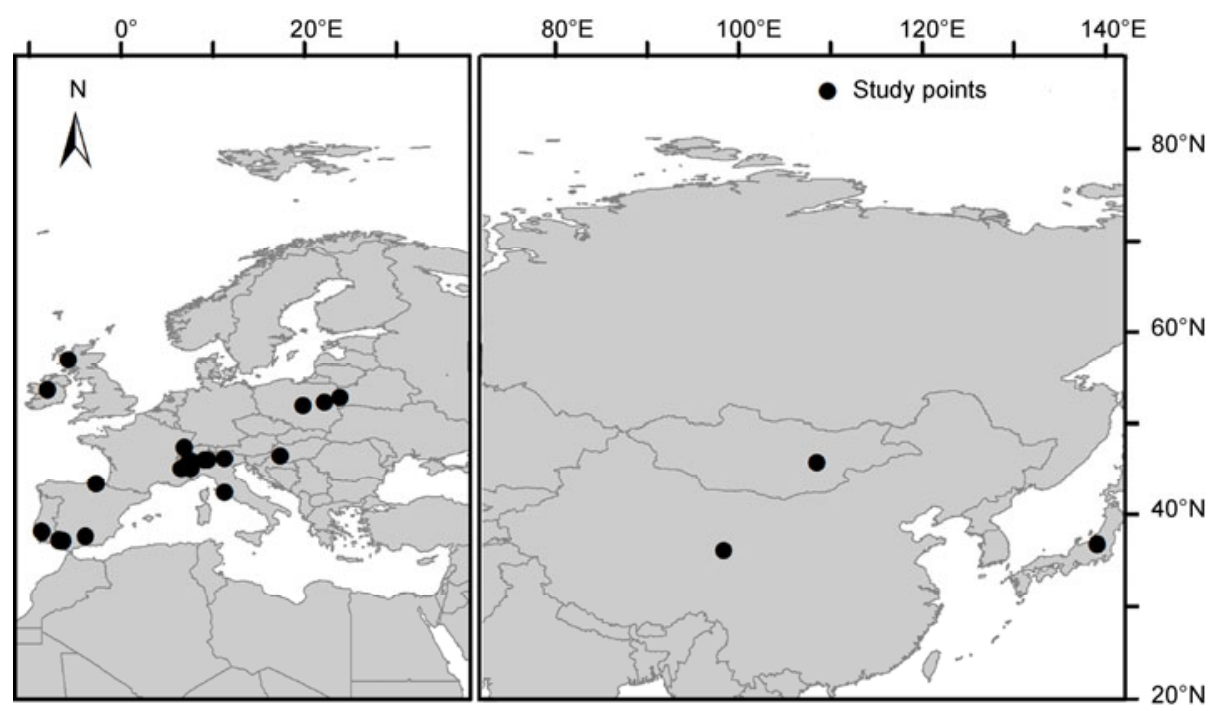

Figure 1 Localities across Eurasia from which data was obtained from publications [12-30]. 
Table 1 Studies of the diet of the Eurasian badger (Meles meles) in this review with an indication of latitude, longitude where the study took place, year, sample size, food items and trophic diversity $\left(H^{\prime}\right)$

\begin{tabular}{|c|c|c|c|c|c|c|c|c|c|c|c|c|}
\hline Author & Locations & $\begin{array}{c}\text { No. of } \\
\text { samples }\end{array}$ & $\begin{array}{c}\text { Earthworm } \\
\text { (RF\%) }\end{array}$ & $\begin{array}{c}\text { Mammals } \\
(\mathrm{RF} \%)\end{array}$ & $\begin{array}{c}\text { Birds } \\
(\mathrm{RF} \%)\end{array}$ & $\begin{array}{l}\text { Insects } \\
(\mathrm{RF} \%)\end{array}$ & $\begin{array}{l}\text { Amphibian } \\
(\mathrm{RF} \%)\end{array}$ & $\begin{array}{c}\text { Reptiles } \\
(\mathrm{RF} \%)\end{array}$ & $\begin{array}{l}\text { Fruits } \\
\text { (RF\%) }\end{array}$ & $\begin{array}{c}\text { Mollusks } \\
(\mathrm{RF} \%)\end{array}$ & $\begin{array}{l}\text { Others } \\
(\mathrm{RF} \%)\end{array}$ & $H^{\prime}$ \\
\hline 1 Balestrieri (2004) & $45^{\circ} 2^{\prime} \mathrm{N}, 7^{\circ} 43^{\prime} \mathrm{E}$ & 199 & 44.93 & 6.58 & 3.01 & 18.36 & 11.24 & 0.30 & 10.68 & 4.66 & 0.24 & 1.61 \\
\hline 2 Balestrieri (2009) & $45^{\circ} 53^{\prime} \mathrm{N}, 7^{\circ} 37^{\prime} \mathrm{E}$ & 222 & 44.58 & 2.22 & 0.25 & 20.2 & 11.33 & 0.49 & 20.94 & 0 & 0 & 1.38 \\
\hline 3 Boesi (2002) & $46^{\circ} 01^{\prime} \mathrm{N}, 9^{\circ} 09^{\prime} \mathrm{E}$ & 118 & 8.04 & 6.92 & 1.79 & 47.99 & 0.67 & 0.22 & 34.38 & 0 & 0 & 1.23 \\
\hline 4 Cleary (2009) & $53^{\circ} 31 \mathrm{~N}, 7^{\circ} 59^{\prime} \mathrm{W}$ & 686 & 43.12 & 1.17 & 0.59 & 41.95 & 5.7 & 0 & 6.29 & 1.17 & 0 & 1.20 \\
\hline 5 Fedriani (1998) & $37^{\circ} 10^{\prime} \mathrm{N}, 6^{\circ} 23^{\prime} \mathrm{W}$ & 145 & 0 & 30.21 & 1.37 & 42.64 & 7.64 & 5.63 & 12.52 & 0 & 0 & 1.40 \\
\hline 7 Fischer (2005) & $47^{\circ} 19^{\prime} \mathrm{N}, 6^{\circ} 58^{\prime} \mathrm{W}$ & 1436 & 28.02 & 4.48 & 0 & 19.02 & 0 & 0 & 43.03 & 0 & 5.45 & 1.33 \\
\hline 8 Gonavalski (2000) & $52^{\circ} 43^{\prime} \mathrm{N}, 23^{\circ} 54^{\prime} \mathrm{E}$ & 141 & 24.43 & 15.66 & 0 & 17.94 & 0 & 0 & 36.75 & 0 & 5.22 & 1.46 \\
\hline 9 Gonavalski (2000) & $52^{\circ} 13^{\prime} \mathrm{N}, 22^{\circ} 13^{\prime} \mathrm{E}$ & 281 & 31.9 & 15.19 & 0 & 27.9 & 0 & 0 & 19.76 & 0 & 5.25 & 1.48 \\
\hline 10 Gonavalski (2000) & $51^{\circ} 48^{\prime} \mathrm{N}, 19^{\circ} 53^{\prime} \mathrm{E}$ & 66 & 24.18 & 11.12 & 1.51 & 41.28 & 13.52 & 0.37 & 4.35 & 0 & 3.67 & 1.56 \\
\hline 11 Kaneko (2006) & $36^{\circ} 45^{\prime} \mathrm{N}, 139^{\circ} 15^{\prime} \mathrm{E}$ & 82 & 33.55 & 1.94 & 4.52 & 21.29 & 0.65 & 0 & 35.48 & 2.58 & 0 & 1.41 \\
\hline 12 Kruuk (1981) & $56^{\circ} 53^{\prime} \mathrm{N}, 5^{\circ} 49^{\prime} \mathrm{W}$ & 2159 & 26.37 & 6.49 & 2.41 & 39.98 & 1.49 & 0 & 19.69 & 0 & 3.57 & 1.49 \\
\hline 13 Lanszki (2004) & $46^{\circ} 24^{\prime} \mathrm{N}, 17^{\circ} 27^{\prime} \mathrm{E}$ & 156 & 17.55 & 5.16 & 1.21 & 44.97 & 23.39 & 1.03 & 6.33 & 0 & 0.36 & 1.45 \\
\hline 14 Lucherini (1995) & $45^{\circ} 04^{\prime} \mathrm{N}, 6^{\circ} 39^{\prime} \mathrm{E}$ & 76 & 22.44 & 11.21 & 0.93 & 59.82 & 0 & 0 & 5.6 & 0 & 0 & 1.09 \\
\hline 15 Marassi (2002) & $46^{\circ} 01^{\prime} \mathrm{N}, 9^{\circ} 30^{\prime} \mathrm{E}$ & 147 & 20.04 & 6.41 & 1.45 & 29.06 & 0 & 0 & 41.28 & 1.15 & 0.61 & 1.37 \\
\hline 16 Martin (1995) & $37^{\circ} 07^{\prime} \mathrm{N}, 6^{\circ} 44^{\prime} \mathrm{W}$ & 530 & 0 & 26.82 & 1.42 & 54.36 & 6.99 & 7.13 & 3.28 & 0 & 0 & 1.23 \\
\hline 17 Murdoch (2010) & $45^{\circ} 43^{\prime} \mathrm{N}, 108^{\circ} 39^{\prime} \mathrm{E}$ & 116 & 0 & 14.77 & 3.98 & 63.64 & 0 & 12.5 & 5.11 & 0 & 0 & 1.11 \\
\hline 18 Prignioni (2008) & $46^{\circ} 07^{\prime} \mathrm{N}, 11^{\circ} 20^{\prime} \mathrm{E}$ & 230 & 11.90 & 4.84 & 2.22 & 27.33 & 2.56 & 0 & 51.14 & 0 & 0 & 1.28 \\
\hline 19 Remonti (2007) & $45^{\circ} 38^{\prime} \mathrm{N}, 7^{\circ} 20^{\prime} \mathrm{E}$ & 228 & 0 & 41.58 & 11.7 & 14.98 & 0 & 0 & 26.6 & 0 & 5.14 & 1.41 \\
\hline 20 Zabala (2002) & $43^{\circ} 23^{\prime} \mathrm{N}, 2^{\circ} 40^{\prime} \mathrm{W}$ & 80 & 29.68 & 3.26 & 0 & 37.21 & 0 & 0 & 25.58 & 0 & 4.23 & 1.32 \\
\hline 21 Rosalino (2005) & $38^{\circ} 06^{\prime} \mathrm{N}, 8^{\circ} 36^{\prime} \mathrm{W}$ & 282 & 0 & 1.36 & 0.14 & 66.32 & 0.47 & 0.3 & 31.4 & 0 & 0 & 0.75 \\
\hline 22 This study (2010) & $36^{\circ} 40^{\prime} \mathrm{N}, 100^{\circ} 48^{\prime} \mathrm{E}$ & 162 & 0 & 3.34 & 5.41 & 68.45 & 0 & 13.54 & 8.87 & 0.4 & 0 & 1.04 \\
\hline
\end{tabular}

We used the relative frequency of occurrence to access the diet of badgers. The undigested residues were distinguished into nine food categories: earthworm, birds, mammals, insects, amphibians, reptiles, fruits, mollusk and others including leaves, roots, garbage and unidentified fraction. We measured trophic diversity of badgers with Shannon-Wiener Index $\left(H^{\prime}\right)$ :

$$
H^{\prime}=-\sum P_{i} \times \log \left(P_{i}\right),
$$

where $P_{i}$ is the relative frequency of occurrence of a given food item $i$.

\subsection{Biogeographical variables}

Biogeographical variables at each site included temperature, precipitation, depth of snow cover, inferred primary productivity, elevation, aspect, latitude and longitude. Mean temperature $\left(T_{\text {mean }}\right)$, mean precipitation $\left(P_{\text {mean }}\right)$, mean temperature in the warm season $\left(T_{\text {warm }}\right)$ and cold season $\left(T_{\text {cold }}\right)$, and mean precipitation in the wet season $\left(P_{\text {wet }}\right)$ and dry season $\left(P_{\text {dry }}\right)$ were extracted from the WORLDCLIM database (http://www.worldclim.org/current) from 1955-2000 for all study areas. We used annual mean net primary productivity (NPP) from 1980-2000 as a measure of local productivity. Data on NPP were obtained from the Global Inventory Monitoring and Modeling Studies data set with a spatial resolution of $1 \mathrm{~km} \times 1 \mathrm{~km}$ (http://glcf.umiacs.umd.edu/data/ gimms/). We obtained satellite-derived data on snow cover (snow depth) from the Global Ecosystem Database V2.0 (http://www.ngdc.noaa.gov). Data on demography was from http://srtm.csi.cgiar.org, where elevation, latitude and longitude, aspects of each study site were extracted. Human influence was measured using the human influence index (HII) [33]. HII evaluates the influence of human activities on ecosystems using eight measures of human presence: population density/ $\mathrm{km}^{2}(0-10)$, score of railroads (8 and 0$)$, score of major roads $(8,4$ and 0$)$, score of navigable rivers ( 4 and 0$)$, score of coastlines ( 4 and 0 ), score of nighttime stable lights values $(0,3,6$ and 10$)$, urban polygons (10 and 0 ) and land cover categories (10,8,3 and 0). The value of HII is the sum of the score of the eight factors and it ranges from 0-64, where a zero value represents no human influence and 64 represents the maximum human influence. Data on HII was obtained from the Socioeconomic Data and Applications Center with spatial resolution of $30 \mathrm{~s}$ (http://sedac. ciesin.columbia.edu/wildareas/).

\subsection{Data analysis}

We used Kolmogorov-Smirnov Test to check data normality and transformed data when necessary [34]. To describe the overall pattern of badger diets, we reduced the nine prey 
groups into orthogonal factors using a Principal Components Analysis (PCA). Varimax Normalized Rotated Method was used to eliminate the collinearity among variables. We used Pearson Correlation Analysis to reveal the relationship between PCA factors and latitude or elevation. The PCA factors were used as dependent variables in Linear Regression Analyses while the latitude and elevation were included as predictors. Regression was also used to examine the relationship between trophic diversity index and latitude, elevation and aspect. We analyzed the influence of food categories and environmental variables on the trophic diversity index through multiple regression, where $H^{\prime}$ was the dependent variable and food category and environmental variables were predictors. All statistical analyses were performed in SPSS 16.0 (SPSS Inc., USA) and alpha was 0.05.

\section{Results}

\subsection{Trophic diversity}

Earthworm was not the main food item for badgers. Instead, insects and fruit were the main food categories consumed by badgers across all studies (Table 1). A PCA using nine main prey items generated four orthogonal factors with eigenvalues greater than 1 accounting for more than $82 \%$ of the variance (Table 2). The first factor represented an increasing frequency of earthworms and 'other food types' and decreasing frequency of insects and reptiles. The second factor showed a gradient of diet with a high frequency of mammals and birds and low frequency of insects. The third factor represented an increasing frequency of amphibians and decreasing frequency of fruit. The fourth factor showed an increasing frequency of mollusks and decreasing frequency of birds. Latitude was significantly correlated with factor 1 (factor 1 equaled $-4.078+0.090 \times$ latitude, $R^{2}$ $\left.=0.269, F_{21}=7.352, P=0.01\right)$ (Figure 2(a)). Elevation and aspect were excluded from the model.

Multiple Regression Analysis between the PCA factors and environmental variables showed the variables $P_{\text {dry }}$ and HII were retained in the final model for factor 1 , where factor $1=-1.820+0.006 \times P_{\text {dry }}+0.045 \times \mathrm{HII}\left(R^{2}=0.500, F_{21}\right.$ $=9.488, P=0.001)$ (Figure 2 (b) and (c)). $T_{\text {mean }}, T_{\text {warm }}, T_{\text {cold }}$, $P_{\text {mean }}, P_{\text {dry }}$, depth of snow cover and NPP were not retained in the model.

Table 2 Principal Component Analysis (PCA) of Eurasian badger diet expressed as relative frequency of occurrence, and Pearson correlation values ( $r$ ) of latitude and elevation with PCA factors

\begin{tabular}{|c|c|c|c|c|}
\hline \multirow{2}{*}{ Variables } & \multicolumn{4}{|c|}{ Relative frequency of occurrence ${ }^{a}$} \\
\hline & Factor 1 & Factor 2 & Factor 3 & Factor 4 \\
\hline Earthworm & 0.70 & -0.53 & 0.26 & -0.02 \\
\hline Birds & -0.09 & 0.73 & -0.13 & 0.53 \\
\hline Insects & -0.92 & -0.12 & 0.08 & 0.03 \\
\hline Amphibian & 0.12 & -0.14 & $0.88 *$ & -0.02 \\
\hline Reptiles & -0.81 & 0.23 & 0.11 & -0.12 \\
\hline Fruits & 0.43 & -0.16 & -0.79 & -0.07 \\
\hline Mollusks & 0.08 & 0.05 & 0.02 & 0.94 \\
\hline Others & 0.59 & 0.37 & -0.21 & -0.47 \\
\hline Eigenvalue & 2.54 & 1.91 & 1.56 & 1.41 \\
\hline Variance explained (\%) & 28.23 & 21.23 & 17.29 & 15.63 \\
\hline$r_{\text {elevation }}$ & -0.29 & 0.03 & -0.26 & 0.01 \\
\hline
\end{tabular}

a) $*, P<0.05$.
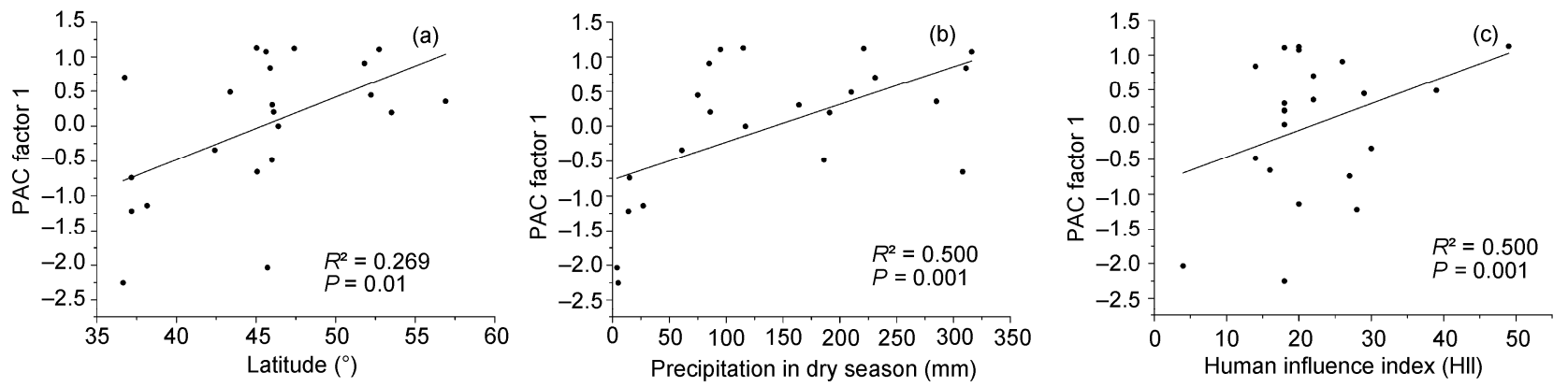

Figure 2 Relationship between PCA factor 1 and (a) latitude, (b) precipitation in dry season and (c) human influence index (HII) for the Eurasian badger. 


\subsection{Factors affecting trophic diversity}

Multiple Regression Analysis between the $H^{\prime}$ trophic diversity index and food categories indicated $H^{\prime}$ was negatively correlated with insects and fruits $\left(R^{2}=0.702, F_{21}=22.362\right.$, $P=0.000$ ) (Figure 3 ). The analysis through multiple regression of $H^{\prime}$ and geographical variables such as latitude, elevation and aspect revealed there was a significant positive correlation of $H^{\prime}$ with latitude $\left(R^{2}=0.199, F_{21}=4.97, P=\right.$ 0.037) (Figure 4). A Multiple Regression Analysis between $H^{\prime}$ and environmental variables indicated that the HII was positively correlated with $H^{\prime}\left(R^{2}=0.204, F_{21}=5.118, P=\right.$ 0.035) (Figure 4).

\section{Discussion}

Eurasian badgers have a flexible diet: fruits, annelids, mollusks, insects, amphibians, reptiles, birds and mammals are all potential preys for badgers. Only in England, badger mainly preys on earthworms [11]. While in most of other localities, insects, mammals and fruits are the main food categories in the badger diet [14,23-25]. The geographical distribution of badger prey may be partly explained by differences in the availability of food resources [35]. In arid areas at low latitude, insects and reptiles are more abundant whereas earthworms are richer in humid areas at high latitudes. Thus, earthworms were eaten by badgers more frequently in humid and high latitude areas $[14,21,26]$ whereas insects and reptiles were predated on in arid areas at low atitudes $[25,28,29]$. Other carnivore species also display
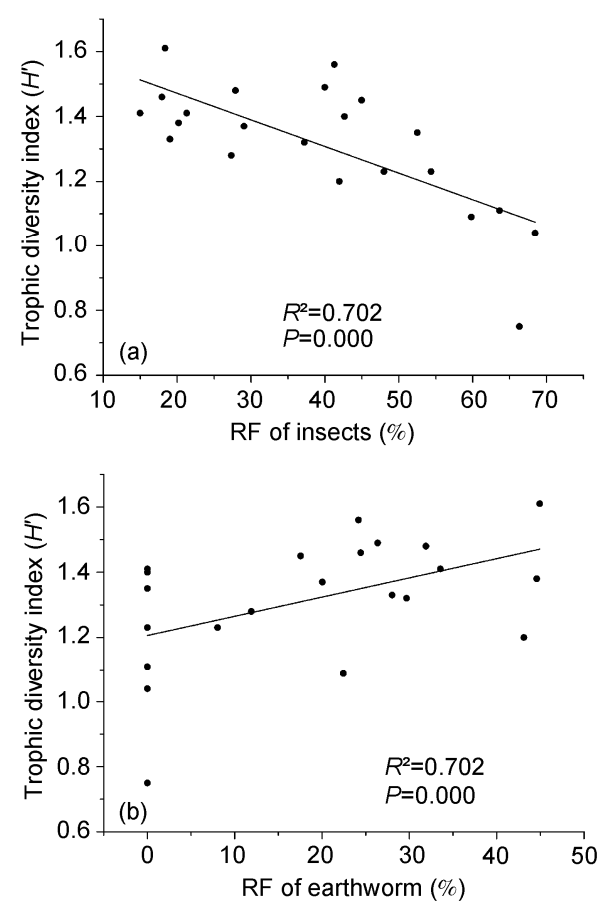

Figure 3 Relationship between trophic diversity index $\left(H^{\prime}\right)$ and (a) insects and (b) earthworms for the Eurasian badger.
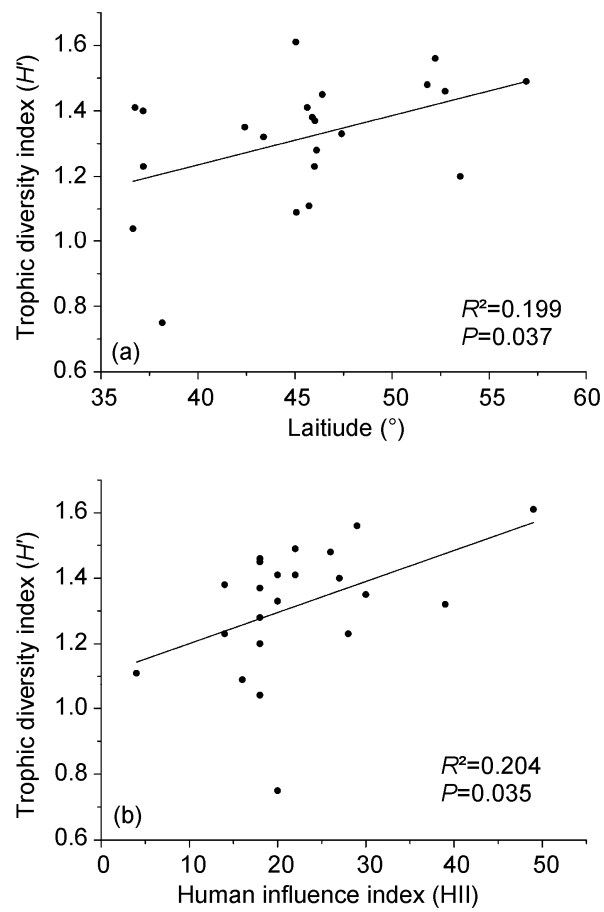

Figure 4 Relationship between trophic diversity index $\left(H^{\prime}\right)$ and (a) latitude and (b) human influence index (HII) for the Eurasian badger.

lanalogic flexibility and the characteristic of switching of main food items across their spatial distribution. For example, wildcats mainly eat rodents at northern latitudes but prey on rabbits at southern latitudes [2]. The same pattern of rabbit intake has been shown for red fox [4]. Martens shift from preying on mammals to eating fruit when fruit is abundant [3].

Our results indicate that badgers are generalist foragers across their distribution, according to the definition by Hanski [36]. Badgers should not be considered earthworm specialist predator because earthworms are the principal prey of badgers only at several localities. It is clear that badgers often exploit local resources because reptiles, mammals, insects and fruits are consumed by badgers at an unexpectedly high frequency when these prey are abundant locally. For instance, fruits (mainly olives, pears and figs) are principal food for badgers in the cork oak woodland in Portugal [27]. Badger mainly consumes insects in arid area of Mongolia [25]. Lagomorphs, insects and fruit are main food items in Doñana National Park in Spain [28].

Over a broad geographical area, trophic diversity in wild animal is usually affected by latitude. Researches on the trophic ecology of several species support the prediction of a decreasing trophic diversity at higher latitude. The diversity of the Montagu's harrier (Circus pygargus) diet decreased from south to north in northern hemisphere [37]. Diets of wildcats also show similar patterns [2]. However, badger diets show an opposite trend. The lower trophic diversity in badger diets was found at more southern latitudes. Goszczynski et al. [23] also found in Europe 
badger food niche was broadest in temperate zone and was narrow at south latitude. Zhou et al. revealed the marten has higher trophic diversity and niche breadth at south latitude because insects are not the main prey of martens, but insects are the principal prey items for badgers especially in southern area [3]. Therefore, it is not surprising that trophic diversity of badgers shows an opposite trend to that of other carnivores.

Primary productivity is often correlated with species and dietary diversity. Bird species richness increases with higher primary productivity [38]. Primary productivity is also an important variable for predicting distribution of herbivores and carnivores. Mongolian gazelles (Procapra gutturosa) preferred habitat with intermediate primary productivity [39]. Primary productivity also affects the body mass of roe deer (Capreolus capreolus) in low primary productivity area [40]. The consumption of fruit is significantly correlated with primary productivity in brown bears [6]. However, our results indicate that primary productivity does not affect dietary composition in badgers. A similar result was found in dietary diversity of martens [3]. Zhou et al. [3] found martens only utilize trees bearing fleshy fruits; primary productivity does not truly reflect diet composition of martens. Badger mainly predates on animals whereas the fruits in badger diet are seasonal and complementary. Thus, no relationship is found between badger diet and primary productivity.

Our result also reveals that the trophic diversity of badgers is positively related to the intensity of human influence. Human activities lead to wildlife habitat fragmentation and transformation [41]. Researchers have revealed the abundance of species decreases as human activity increases $[42,43]$. Species diversity and abundance vary distinctly between different habitats, especially for insects [44]. The feeding habitats of badger are more heterogeneous in area under high human influence. When badgers forage during active period, badgers have to cover several different types of habitat patches and capture different categories of foods to sustain themselves every time. This may be the reason for discovering high trophic diversity of badgers in areas of high human influence. Another reason is that badgers have more chances to utilize fruits from gardens. Consuming fruits could lead to higher trophic diversity of martens [3].

In Eurasia, the food spectrum of badgers includes invertebrate, vertebrate, and vegetables; they even adopt to explore the feeding opportunities in human society. Badgers are efficient at exploiting local resources and their trophic diversities have latitude gradients. Therefore, badgers are generalist predators with opportunistic foraging behavior.

This work was supported by Knowledge Innovation International Partnership Project of the Chinese Academy of Sciences (CXTDS2005-4, KSCX2-EW-J-2), the Science and Technology Supporting Project, Ministry of Science and Technology of China (2008BAC39B04), and National Natural Science Foundation of China (30670267, 30430120). We are grateful to Hua Qingjia and Sang Jiejia for help with field surveys and sample collection. We also thank Ji Yang, Xiaoge Ping, Jing Chen, Xiaobo Yang and Jiawei Zhu for advice on our research.

1 Clavero M, Prenda J, Delibes M. Trophic diversity of the otter (Lutra lutra L.) in temperate and Mediterranean freshwater habitats. J Biogeogr, 2003, 30: 761-769

2 Lozano J, Moleon M, Virgos E. Biogeographical patterns in the diet of the wildcat, Felis silvestris Schreber, in Eurasia: Factors affecting the trophic diversity. J Biogeogr, 2006, 33: 1076-1085

3 Zhou Y B, Newman C, Xu W T, et al. Biogeographical variation in the diet of Holarctic martens (genus Martes, Mammalia: Carnivora: Mustelidae): Adaptive foraging in generalists. J Biogeogr, 2011, 38: 137-147

4 Díaz-Ruiz F, Delibes-Mateos M, García-Moreno J L, et al. Biogeographical patterns in the diet of an opportunistic predator: The red fox Vulpes vulpes in the Iberian Peninsula. Mammal Rev, 2011, doi: 10.1111/j.1365-2907.2011.00206.x

5 Grindal S D, Collard T S, Brigham R M, et al. The influence of precipitation on reproduction by myotis bats in British-Columbia. Am Midl Nat, 1992, 128: 339-344

6 Bojarska K, Selva N. Spatial patterns in brown bear Ursus arctos diet: The role of geographical and environmental factors. Mammal Rev, 2011, 4: 120-142

7 Daan S, Tinbergen J M. Adaptation of life histories. In: Krebs J R, Davies N B, eds. Behavioural Ecoloy: An Evolutionary Approach. Oxford UK: Wiley-Blackwell, 1997

8 Nowak R M. Walker's Mammals of the World, 6th ed. Baltimore: Johns Hopkins University Press, 1999

9 Feng Z. Eurasian Badger Meles meles. In: Feng Z J, ed. Mammalia in Tibet (in Chinese). Beijing: Science Press, 1986. 161-162

10 Abramov A. Variation of the baculum structure of the Palaearctic badger (Carnivora, Mustelidae, Meles). Russian J Theriol, 2002, 1: 57-60

11 Dasilva J, Woodroffe R, Macdonald D W. Habitat, food availability and group territoriality in the European Badger, Meles meles. Oecologia, 1993, 95: 558-564

12 Zabala J, Garin I, Zuberogoitia I, et al. Habitat selection and diet of badgers (Meles meles) in Biscay (northern Iberian Peninsula). Ital J Zool, 2002, 69: 233-238

13 Lucherini M, Crema G. Seasonal variation in the food habits of badgers in an Alpine valley. Hystrix, 1995, 7: 165-171

14 Balestrieri A, Remonti L, Prigioni C. Diet of the Eurasian badger (Meles meles) in an agricultural riverine habitat (NW Italy). Hystrix, 2004, 15: 3-12

15 Prigioni C, Balestrieri A, Remonti L, et al. Differential use of food and habitat by sympatric carnivores in the eastern Italian Alps. Ital J Zool, 2008, 75: 173-184

16 Balestrieri A, Remonti L, Prigioni C. Exploitation of food resources by the Eurasian badger (Meles meles) at the altitudinal limit of its Alpine range (NW Italy). Zool Sci, 2009, 26: 821-827

17 Remonti L, Balestrieri A, Prigioni C. Role of fruits in the diet of small mustelids (Mustela sp.) from the western Italian Alps. Eur J Wildl Res, 2007, 53: 35-39

18 Marassi M, Biancardi C. Diet of the Eurasian badger (Meles meles) in an area of the Italian Prealps. Hystrix, 2002, 13: 19-28

19 Boesi R, Biancardi C M. Diet of the Eurasian badger Meles meles (Linnaeus, 1758) in the natural reserve of Lago di Piano, northern Italy. Mamm Biol, 2002, 67: 120-125

20 Del Bove E, Isotti R. The European badger (Meles meles) diet in a Mediterranean area. Hystrix, 2001, 12: 19-25

21 Lanszki J. Diet of badgers living in a deciduous forest in Hungary. Mamm Biol, 2004, 69: 354-358

22 Cleary G, Corner L, O'Keeffe J, et al. The diet of the badger Meles meles in the Republic of Ireland. Mamm Biol, 2009, 74: 438-447

23 Goszczynski J, Jedrzejewska B, Jedrzejewski W. Diet composition of badgers (Meles meles) in a pristine forest and rural habitats of Poland compared to other European populations. J Zool, 2000, 250: 495-505 
24 Kaneko Y, Maruyama N, Macdonald D W. Food habits and habitat selection of suburban badgers (Meles meles) in Japan. J Zool, 2006, 270: 78-89

25 Murdoch J D, Buyandelger S. An account of badger diet in an arid steppe region of Mongolia. J Arid Environ, 2010, 74: 1348-1350

26 Kruuk H, Parish T. Feeding specialization of the European Badger Meles meles in Scotland. J Anim Ecol, 1981, 50: 773-788

27 Rosalino L M, Loureiro F, MacDonald D W, et al. Dietary shifts of the badger (Meles meles) in Mediterranean woodlands: An opportunistic forager with seasonal specialisms. Mamm Biol, 2005, 70: 12-23

28 Fedriani J M, Ferreras P, Delibes M. Dietary response of the Eurasian badger, Meles meles, to a decline of its main prey in the Donana National Park. J Zool, 1998, 245: 214-218

29 Martin R, Rodriguez A, Delibes M. Local feeding specialization by Badgers (Meles meles) in a Mediterranean environment. Oecologia, 1995, 101: 45-50

30 Fischer C, Ferrari N, Weber J M. Exploitation of food resources by badgers (Meles meles) in the Swiss Jura mountains. J Zool, 2005, 266: 121-131

31 Virgos E, Llorente M, Cortes Y. Geographical variation in genet (Genetta genetta L.) diet: A literature review. Mammal Rev, 1999, 29: 117-126

32 Roper T, Lups P. Diet of badgers (Meles meles) in central Switzerland: An analysis of stomach contents. Mamm Biol, 1995, 60: 9-19

33 Sanderson E W, Jaiteh M, Levy M A, et al. The human footprint and the last of the wild. Bioscience, 2002, 52: 891-904

34 Underwood A J. Experiments in Ecology. London: Cambridge
University Press, 1996

35 Chapman R F. The Insects: Structure and Function. London: Cambridge University Press, 1998

36 Hanski I, Hansson L, Henttonen H. Specialist predators, generalist predators, and the microtine rodent cycle. J Anim Ecol, 1991, 60: 353-367

37 Terraube J, Arroyo B. Factors influencing diet variation in a generalist predator across its range distribution. Biodivers Conserv, 2011, 20: 2111-2131

38 Lee P F, Ding T S, Hsu F H, et al. Breeding bird species richness in Taiwan: Distribution on gradients of elevation, primary productivity and urbanization. J Biogeogr, 2004, 31: 307-314

39 Mueller T, Olson K A, Fuller $\mathrm{T} \mathrm{K}$, et al. In search of forage: Predicting dynamic habitats of Mongolian gazelles using satellitebased estimates of vegetation productivity. J Appl Ecol, 2008, 45: 649-658

40 Pettorelli N, Gaillard J M, Mysterud A, et al. Using a proxy of plant productivity (NDVI) to find key periods for animal performance: The case of roe deer. Oikos, 2006, 112: 565-572

41 Vitousek P M, Mooney H A, Lubchenco J, et al. Human domination of earth's ecosystems. Science, 1997, 277: 494-499

42 Laliberte A S. Ripple W J. Range contractions of North American carnivores and ungulates. Bioscience, 2004, 54: 123-138

43 Lopes M A, Ferrari S F. Effects of human colonization on the abundance and diversity of mammals in eastern Brazilian Amazonia. Conserv Biol, 2000, 14: 1658-1665

44 Janzen D H, Schoener T W. Differences in insect abundance and diversity between wetter and drier sites during a tropical dry season. Ecology, 1968, 49: 96-110

Open Access This article is distributed under the terms of the Creative Commons Attribution License which permits any use, distribution, and reproduction in any medium, provided the original author(s) and source are credited.

\section{Appendix}

\section{S1 The methods and results of badger diet in Qinghai-Tibetan Plateau, China}

Methods: Data in China was from our own fieldwork. From October 2008 to October 2010, the study was conducted in the Qinghai Lake Basin $\left(36^{\circ} 39^{\prime} \mathrm{N}, 100^{\circ} 49^{\prime} \mathrm{E}\right)$ on the Qinghai-Tibetan Plateau. We collected scats of badgers in typical latrine once a week throughout the whole study period. Badger-like scats found on the ground were discarded, so as were old or visibly weathered scats. Collection from a latrine is considered as one sample during a collection. Scat samples were stored individually in labeled polyethylene bags at $-12^{\circ} \mathrm{C}$ before analysis. Prior to analysis, scats were thawed, oven dried at $50^{\circ} \mathrm{C}$ for $48 \mathrm{~h}$, and then weighed. They were soaked in water and thoroughly washed through two sieves with mesh sizes of $5 \mathrm{~mm}$ and $1 \mathrm{~mm}$ respectively. The residue of undigested remains was put into a large shallow tray, and allocated to one of following categories: mammals, birds, reptiles, insects, fruits and other vegetation materials. Rinse water was discarded because there was no earthworm found in badger habitat according to our field survey. We also inspected samples under microscope to observe whether there are any remains of earthworms.

Results: We analyzed 162 scats in total, which contained insects, mammals, birds, reptiles, fruits and mollusk. There were average 3.91 items per scat. Insects occurred most frequently, its frequency of occurrence (FO) and relative frequency (RF) were $100 \%$ and $68.45 \%$, respectively. We identified insects eaten by badger were mainly from three orders: Coleoptera, Orthoptera and Hymenoptera respectively. Mammal remains were mainly plateau pika (Ochotona curzoniae); its FO and RF were $11.73 \%$ and 3.95\%, respectively. Bird remains occurred in scats included mostly bones, feather fragments, bills and egg. Birds' FO and RF in scats were $17.90 \%$ and $6.30 \%$, respectively. Reptile found in faeces was Qinghai toad-headed agamid lizard (Phrynocephalus vlangalii). Its FO and RF were $39.51 \%$ and $13.31 \%$, respectively. The FO and RF of fruits of (Ephedrna intermedia) in badger diet were $25.9 \%$ and $8.87 \%$, respectively. No earthworm was found in the scats of badgers. 